\title{
Using the modern CNC controllers capabilities for estimating the machining forces during the milling process
}

\author{
Radu-Eugen Breaz ${ }^{1, *}$ and Sever-Gabriel Racz ${ }^{1}$ \\ ${ }^{1}$ Lucian Blaga University of Sibiu, Engineering Faculty, Emil Cioran 4, 550025 Sibiu, Romania
}

\begin{abstract}
Machining forces can nowadays be measured by using 3D dynamometers, which are usually very expensive devices and hardly available for most of the CNC machine-tools users. On the other hand, modern CNC controllers have nowadays the ability to display and save many outputs within the machining process, such as the currents or even the torques at the shaft's level for the feed motors on each axis. These outputs can be used for estimating the machining forces, but it is to be noticed that the above-mentioned currents and torques are proportional with the overall resistant forces, which includes not only technological forces, but also friction, inertial and pre-tensioning forces. This paper presents an approach for estimating the machining forces during a milling process, by using the outputs stored in the CNC controller and separating the effects of technological forces from the other forces involved in the process. The separation was made by running two sets of experiments, one set for dry-run regime and the other one for machining regime.
\end{abstract}

\section{Introduction}

Measuring the cutting forces is important with many respects. This measurement could be performed by using 3D dynamometers (Kistler), but this approach is suitable mostly for research facilities. Dynamometers are expensive and are reported to be easily damaged by cooling liquids. Consequently, alternative methods for measuring forces were developed. One of the most used method involves indirect measurements, by measuring the currents within feed and/or spindle motors using current sensors $[1,2]$. Other approaches are based upon the development of special milling sensors [3, 4], systems with optical data transmission [5] or upon strain gauges [6]. There are also reported some solutions of non-commercial, special dynamometers developed by the research teams [7].

Modern CNC controllers can display and save many outputs within the machining process, such as the currents or even the torques at the shaft's level for the feed motors on each axis. These outputs can be used for estimating the machining forces, but it is to be noticed that the above-mentioned currents and torques are proportional with the overall resistant forces, which includes not only technological forces, but also friction, inertial and pre-tensioning forces.

*Corresponding author: radu.breaz@ulbsibiu.ro 


\section{Static torque and technological force}

Usually, for a CNC machining centre, the feed drives on $\mathrm{X}$ and $\mathrm{Y}$ axes are composed of a rotary permanent magnet synchronous servomotor as actuation device and a recirculating ball screw as the solution for converting the rotary motion of the servomotor into linear slide motion. 1.

The schematic diagram of a horizontal (for $\mathrm{X}$ and $\mathrm{Y}$ axes) feed drive is presented in figure

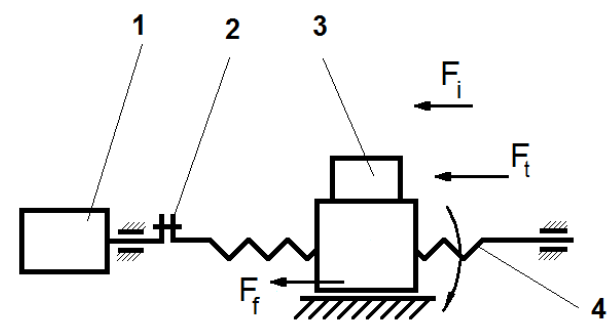

Fig. 1. Schematic loads diagram for a horizontal $\mathrm{CNC}$ feed drive.

The notations from figure 1 have the following significations:

1 - drive motor; 2 - axial coupling; 3 - horizontal slide and part; 4 - lead ball-screw.

The total static torque for a horizontal feed drive may be calculated with the following relation:

$$
M_{s t}=\frac{\left.\left[F_{t}+F_{f}\right)\right] \cdot p}{2 \pi \cdot i \cdot \eta_{t o t}}+M_{p r}=\frac{\left.\left[F_{t}+\mu \cdot m \cdot g\right)\right] \cdot p}{2 \pi \cdot i \cdot \eta_{t o t}}+M_{p r}
$$

where:

$\mathrm{M}_{\mathrm{st}}$ - total static torque [Nm], $\mathrm{F}_{t}-$ technological force $[\mathrm{N}], \mathrm{F}_{\mathrm{f}}-$ friction force $[\mathrm{N}], \mathrm{F}_{\mathrm{i}}-$ inertial force $[\mathrm{N}], \mathrm{m}$ - total mass (machine slide and workpiece) $[\mathrm{kg}], \mu$ - friction coefficient, $\mathrm{g}-$ gravity acceleration $\left[\mathrm{m} / \mathrm{s}^{2}\right], \mathrm{p}$ - lead ball-screw step $[\mathrm{mm}], \mathrm{i}$ - transfer ratio between rotational motor and machine slide, $\eta_{\text {tot }}-$ total efficiency of the mechanical transmission between rotational motor and machine slide, $\mathrm{M}_{\mathrm{pr}}$ - pre-tensioning torque of the nut of the main ball-screw system [N].

Taking into consideration the fact that, for the CNC machining centre used for this research the rotational motors for $\mathrm{X}$ and $\mathrm{Y}$ axes are directly coupled with the lead screws $(\mathrm{i}=1)$, the following relationships regarding the static torques on each axis may be written:

$$
M_{s t X, Y}=\frac{\left[F_{t X, Y}+\mu \cdot m_{X, Y} \cdot g\right] \cdot p}{2 \pi \cdot \eta_{s}}+M_{p r X, Y}
$$

Dynamic torques are also appearing during the milling process, on the acceleration and deceleration phase (fig. 2). If the data acquisition is done during the constant velocity (constant feed) phase, the effects of the dynamic torque may be neglected.

The notations from figure 2 have the following significations:

$\mathrm{t}_{\mathrm{a}}$ - acceleration time (dynamic torque is positive non-zero);

$\mathrm{t}_{\mathrm{ct}}$ - constant feed time (dynamic torque is zero);

$t_{d}$ - deceleration time (dynamic torque is negative non-zero).

For the proposed approach, it was necessary to unfold the same movements cycle in noload conditions, prior to unfolding it in load conditions, to be able to read and subtract the no-load and load-conditions torques, per the following relation: 


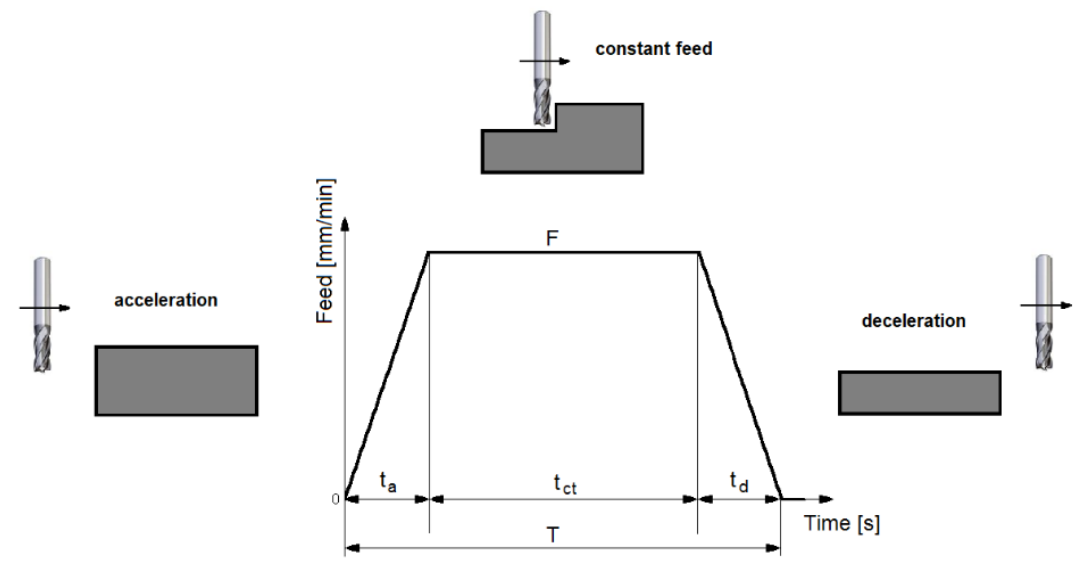

Fig. 2. Velocity profile for a milling cycle.

$$
\Delta M_{s t X, Y}=\frac{\left.\left[F_{t X, Y}+\mu \cdot m_{X, Y} \cdot g\right)\right] \cdot p}{2 \pi \cdot \eta_{s}}+M_{p r X}-\left(\frac{\left.\left[\mu \cdot m_{X, Y} \cdot g\right)\right] \cdot p}{2 \pi \cdot \eta_{s}}+M_{p r X, Y}\right)=\frac{F_{t X, Y} \cdot p}{2 \pi \cdot \eta_{s}}
$$

where:

$\Delta \mathrm{M}_{\mathrm{X}, \mathrm{Y}}-$ difference between static torque in load and no-load conditions.

The technological forces can now be calculated using the relation:

$$
F_{t X, Y}=\frac{2 \pi \cdot \eta_{s}}{p} \cdot \Delta M_{s t X, Y}
$$

\section{Experimental determinations}

A vertical machining centre DMC v 635 ecoline by DMG Mori was used as experimental testbed. It is equipped with Sinumerik 840D CNC controller, which can measure, display and save many process outputs, such as torques on each axis, currents through feed motors and many others.

A single axis milling operation (on $\mathrm{X}$-axis) with the following characteristics was unfolded:

- material: alloyed steel (33MoCr11), $151 \mathrm{HB}$

- cutting tool: flat-end mill from metallic carbide, diameter (d) 10 millimetres, 3 flutes;

- cutting regime: speed (n) 2000 rev/mins, cutting speed $\left(\mathrm{v}_{\mathrm{c}}\right) 62.8 \mathrm{~m} / \mathrm{min}$, cutting feed $\left(\mathrm{v}_{\mathrm{f}}\right)$ $180 \mathrm{~mm} / \mathrm{min}$, feed per tooth $\left(\mathrm{f}_{\mathrm{z}}\right) 0.03 \mathrm{~mm} /$ tooth.

The TRACE function of the CNC controller was used for displaying the outputs.

The TRACE function allows the user to select and capture a selected output within the process for a given interval of time. The size of the interval was chosen of 30 seconds, while the sampling rate $\left(\mathrm{T}_{\mathrm{s}}\right)$ was chosen of 12.5 milliseconds. The sampling rate was chosen to be the smallest one allowed by the size of internal memory of the CNC controller.

Straight lines of 30 millimetres length parallel to $X$ axis were machined, with axial depth of cut $\left(a_{p}\right)$ of 2 millimetres and radial width of cut $\left(a_{e}\right)$ of 10 millimetres were machined (fig $3)$.

The movements cycle for machining the straight lines was programmed in no-load conditions (dry-run), where the tool was moved above the part, with no cutting process occurring and in load conditions, were the cutting process was unfolded. 


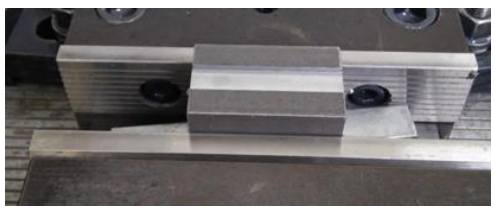

Fig. 3. Machined part.

The output chosen for the first approach was the real torque on X-axis. Figures 4 and 5 show a capture of these torques value in dry-run and in cutting conditions. The data were captured during the constant feed phase, to nullify the influence of the dynamic torque.

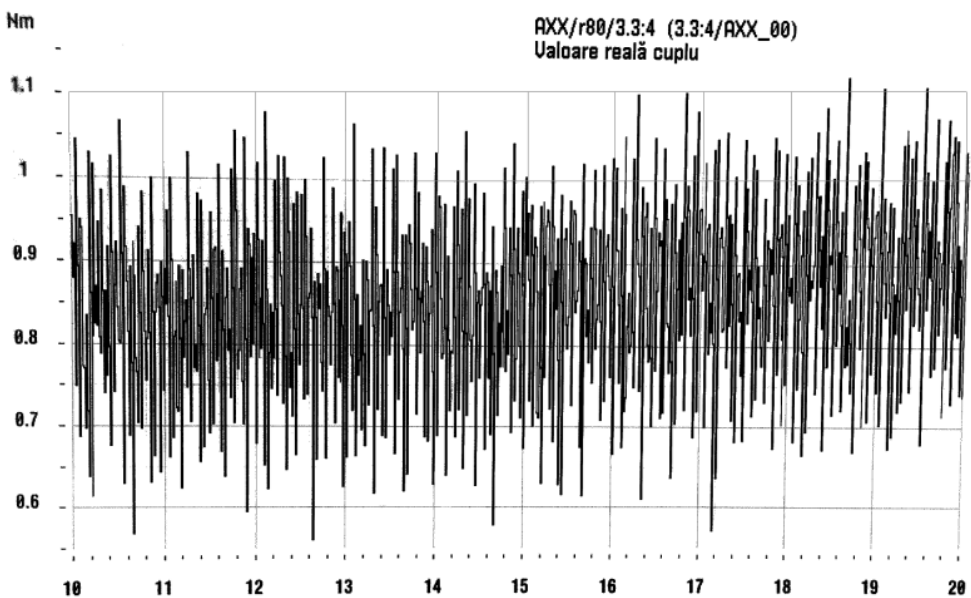

Fig. 4. Torque in dry-run (capture).

From figure 4 it is noticeable that the static torque in dry-run oscillates around a mean value of $0.85 \mathrm{Nm}$. Similarly, in figure 5 one can notice that the static torque in cutting conditions oscillates around the value of $1 \mathrm{Nm}$. Consequently, the value of torque defined by (3) can be expressed as:

$$
\Delta M_{s t X}=1-0.85=0.15 \mathrm{Nm}
$$

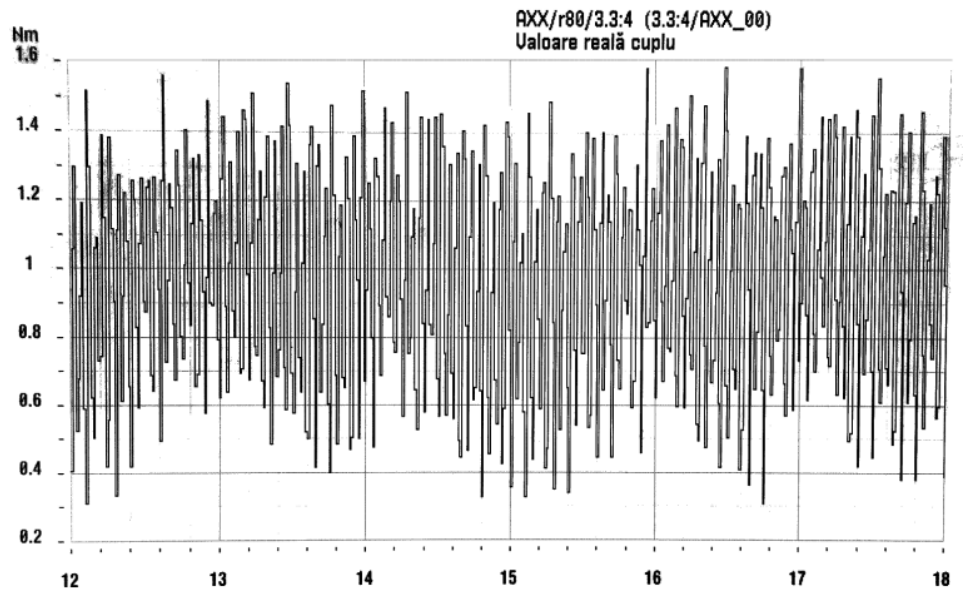

Fig. 5. Torque in cutting conditions (capture). 
The technological force on $\mathrm{X}$ axes can now be calculated using relation (4):

$$
F_{t X}=\frac{2 \pi \cdot \eta_{s}}{p} \cdot \Delta M_{s t X}=\frac{2 \pi \cdot 0.9}{15 \cdot 10^{-3}} \cdot 0.15=56.55 \mathrm{~N}
$$

A second approach involved the acquisition of the currents trough the feed motor of $\mathrm{X}$ axis in dry-run and cutting conditions, presented in figures 6 and 7.

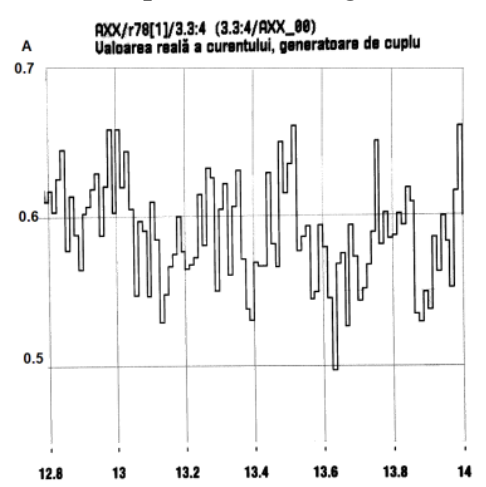

Fig. 6. Current through $\mathrm{X}$-axis motor in dry-run (capture).

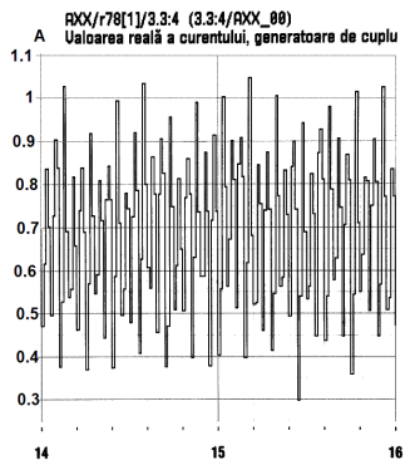

Fig. 7. Current through $\mathrm{X}$-axis motor in cutting conditions (capture).

From figure 6 and 7 it is noticeable that the current in dry-run oscillates around a mean value of $0.6 \mathrm{~A}$, while the current in cutting conditions oscillates around the value of $0.7 \mathrm{~A}$. Consequently, the value of torque defined by (3) can be expressed as:

$$
\Delta M_{\text {st } X}=(0.7-0.6) \cdot K_{t}=(0.7-0.6) \cdot 1.37=0.137 \mathrm{Nm}
$$

It can be noticed that the torque values determined from (5) and (7) are very close to each one. The $\mathrm{K}_{\mathrm{t}}$ value form above $(1.37 \mathrm{Nm} / \mathrm{A})$ represents the torque constant of the $1 \mathrm{FK} 7063$ 2AF71-1RH0 Simotics servomotor.

The cutting force for this milling operation was also determined by using the Kenametal on-line calculator [8] (figure 8). 


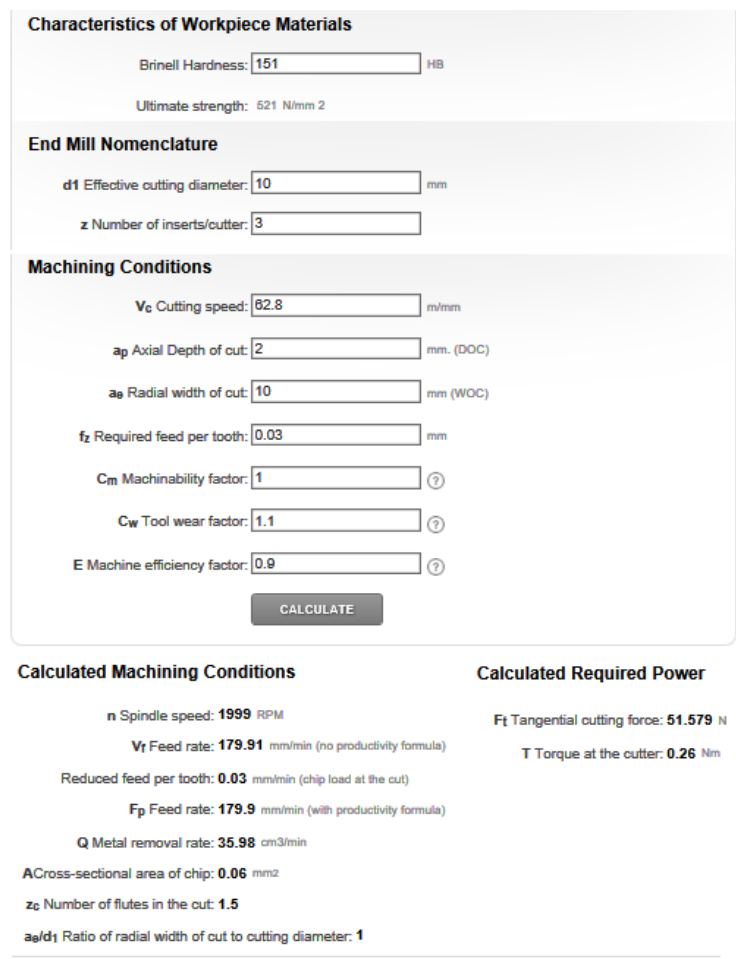

Fig. 8. On-line cutting force calculator

The calculated force $\mathrm{F}_{\mathrm{t}}$, per figure 8 has a value of $51.58 \mathrm{~N}$ which is very close to the experimentally determined one, which has a value of $56.55 \mathrm{~N}$, per (6).

\section{Conclusion}

The proposed method allows the user to determine the cutting forces by using the facilities provided by the modern CNC controllers. The experimentally determined values followed very close the calculated ones. Further researches will be performed to tailor this method for multi-axis cutting operations.

Authors want to thank to Eng. Bogdan Prunel, CNC machining specialist, which provided valuable assistance during the experimental researches.

\section{References}

1. K. Dohyun, J. Doyoung, Precis. Eng. 35 , 143-152 (2011)

2. Y.-H. Jeong, D.-W. Cho, Int. J. Mach. Tools Manuf. 42, 1559-1566 (2002)

3. C. Adolfsson, J-E. Stahl, Int. J. Mach. Tools Manuf. 35, 1715 (1995)

4. C. Andersson, M. Andersson, J.-E. Stahl, Int. J. Mach. Tools Manuf. 51, 67-76 (2011)

5. Y. Ikezaki, Y. Takeuchi, M. Sakamoto, Ann. CIRP, 33, 61 (1984)

6. A.R.H. Shuaib, E. Garcia-Gardea, et al, J. Eng. Ind.-T. ASME, 103(2), 235-240 (1981)

7. G. Totis , G. Wirtz, M. Sortino, D. Veselovac, E. Kuljanic, F. Klocke, Mech. Syst. Signal. Pr. 24, 1844-1857 (2010)

8. $* * * \quad \mathrm{https} / /$ www.kennametal.com/en/resources/engineering-calculators/end-millingcalculators/force-torque-and-power.html 